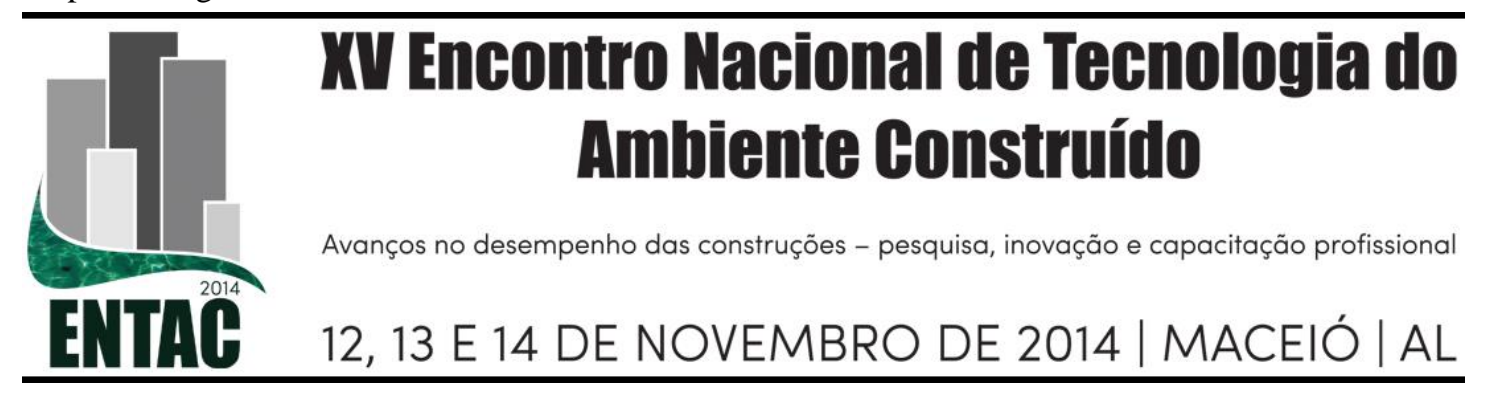

\title{
CONTRIBUIÇÃO DE JANELA COM PERSIANA INTEGRADA AO DESEMPENHO ACÚSTICO DE FACHADA DE EDIFICAÇÃO - SITUAÇÕES DE USO CORRENTE
}

MIRANDA, Fulvio B. (1); IKEDA, Cristina Y. K.(2)

(1) Laboratório de Conforto Ambiental e Sustentabilidade dos Edifícios - Instituto de Pesquisas Tecnológicas do Estado de São Paulo - IPT, telefone (11) 3767-4582, e-mail: bercot@ipt.br (2) Laboratório de Conforto Ambiental e Sustentabilidade dos Edifícios

- Instituto de Pesquisas Tecnológicas do Estado de São Paulo - IPT, e-mail: cristinak@ipt.br

\begin{abstract}
RESUMO
A janela é um elemento importante na composição de fachadas de habitações. Através delas, tem-se o contato visual com o ambiente externo e permite-se a ventilação e entrada de luz nos ambientes internos. Algumas janelas utilizadas atualmente possuem persiana integrada para controle da incidência de radiação solar e da renovação de ar do ambiente. Como a norma brasileira de desempenho de habitações, ABNT NBR 15575, estabelece níveis de desempenho para sistemas de vedações verticais externas, as janelas devem cumprir com requisitos mínimos de isolação sonora. Geralmente estas janelas são ensaiadas com a folha de vidro e as persianas totalmente fechadas, condições tidas como de máximo desempenho. Entretanto, no uso diário, outras configurações, como persiana semiaberta e persiana totalmente recolhida, são utilizadas. Este estudo teve como objetivo verificar se existe uma diferença significativa, em termos de isolação sonora, ao se utilizar a persiana semiaberta ou totalmente recolhida. Através de medições em laboratório, instalando-se a janela em uma parede entre duas câmaras reverberantes, obteve-se diferenças da ordem de $4 \mathrm{~dB}$ entre cada uma das três configurações estudadas. A determinação dos índices de redução sonora, $\mathrm{R}$, foi feita conforme a norma ISO 10140-2:2010 (Acoustics - Laboratory measurement of sound insulation of building elements- Part 2: Measurement of airborne sound insulation) e o cálculo do índice de redução sonora ponderado, Rw, foi feito conforme a norma ISO 717-1:2013 (Acoustics - Rating of sound insulation in buildings and of building elements - Part 1: Airborne sound insulation). Verificou-se que a diferença quanto à isolação sonora é relevante e ela deve ser levada em conta pelo projetista que não deve considerar somente o potencial máximo de isolação sonora como também outras configurações na qual a janela venha a ser utilizada.
\end{abstract}

Palavras-chave: Desempenho acústico, Isolação sonora, Janelas.

\section{ABSTRACT}

The window is an important element in the composition of dwelling facades. Through them, there is visual contact with the external environment in addition to ventilation and light input in the indoor environment. Some windows used nowadays are integrated with rolling shutter boxes in order to control the incidence of solar radiation and the air 
change in the environment. As the Brazilian performance standard for residential buildings, ABNT NBR 15575, establishes performance levels for external vertical sealing systems, windows must meet the minimum requirements for sound insulation. Usually these windows are tested with the glass sheet and the shutter fully closed, conditions considered as maximum performance. However, in daily use, other settings such as half open and fully retracted shutter are used. This study aimed to determine whether there is significant difference in terms of sound insulation, when using the shutter half open or fully retracted. Through laboratory measurements, by installing the window in a wall between two reverberant chambers, differences of the order of $4 \mathrm{~dB}$ among each of the three configurations studied were obtained. The sound reduction index, R, was determined according to the standard ISO 10140-2:2010 (Acoustics Laboratory measurement of sound insulation of building elements - Part 2: Measurement of airborne sound insulation) and the weighted sound reduction index, $R w$, was calculated according to the standard ISO 717-1:2013 (Acoustics - Rating of sound insulation in buildings and of building elements - Part 1: Airborne sound insulation). It was found that the difference in the sound insulation is important and it should be taken into account by the designers who should not only consider the maximum potential of sound insulation but other settings in which the windows are going to be used.

Keywords: Acoustical performance, Sound insulation, Windows.

\section{INTRODUÇÃO}

A norma Edificações habitacionais - Desempenho - Parte 4: Requisitos para os sistemas de vedações verticais internas e externas - SVVIE (ABNT NBR 15575-4, 2013) especifica valores de desempenho acústico mínimo, intermediário e superior para paredes de fachadas de dormitórios, tendo como um dos critérios, o descritor sonoro Rw que é o índice de redução sonora ponderado.

A isolação de sonora de uma parede de fachada é uma composição entre os vários elementos que a compõe. O ponto mais fraco, em termos de isolação de fachadas, costuma ser o caixilho. Através dele, tem-se o contato visual com o ambiente externo e permite-se a ventilação e entrada de luz nos ambientes internos. Algumas janelas utilizadas atualmente possuem persiana integrada para controle da incidência de radiação solar. Este artigo apresenta resultados de ensaios em janela com persiana embutida nos quais as persianas foram mantidas totalmente fechadas, semiabertas e totalmente abertas.

Procurando-se resguardar o sigilo industrial das informações, não serão apresentadas as fotos ou projetos originais do produto ensaiado. As fotos e figuras empregados no presente artigo foram obtidas da internet, de maneira a ilustrar o funcionamento da janela e as condições de ensaio.

\section{INSTALAÇÕES LABORATORIAIS E DESCRIÇÃO DA JANELA}

As medições foram feitas nas câmaras reverberantes do Laboratório de Conforto Ambiental e Sustentabilidades dos Edifícios do IPT. As câmaras atendem às exigências da norma ISO 10140-5:2010 quanto ao formato, e foram previamente qualificadas conforme os procedimentos da referida norma. A janela ensaiada foi instalada em uma parede com vedação pneumática localizada entre os recintos de emissão e recepção. 
O ensaio foi realizado de acordo com o método descrito na norma ISO 10140-2: Acoustics - Laboratory measurement of sound insulation of building elements -- Part 2: Measurement of airborne sound insulation". Foi calculado o Índice de Redução Sonora Ponderado conforme a norma ISO 717-1:2013 Acoustics - Rating of sound insulation in buildings and of building elements - Part 1: Airborne sound insulation.

Foram utilizadas duas caixas acústicas omnidirecionais/dodecaédricas e duas caixas acústicas tipo subwoofer, empregando-se o ruído rosa. O Nível de Pressão Sonora (NPS), para cada $1 / 3$ de oitava, na faixa compreendida entre $100 \mathrm{~Hz}$ e $5.000 \mathrm{~Hz}$, foi determinado em seis diferentes pontos espaciais, nas câmara de emissão e recepção, considerando um NPS máximo de aproximadamente $110 \mathrm{~dB}$ na câmara de emissão. Todos os seis microfones, amplificadores e demais equipamentos de medição/tratamento de dados estavam devidamente calibrados/ajustados dentro das respectivas faixas de tolerância.

A janela alvo do presente estudo, é confeccionada em perfis de alumínio, liga ASTM 6063 , perfis linha 25 , medindo aproximadamente $2,25 \mathrm{~m}$ de largura $\mathrm{x} 1,16 \mathrm{~m}$ de altura, composta por duas folhas móveis, com panos de vidro com $6 \mathrm{~mm}$ de espessura (tipo laminado, PVB comum, duas lâminas de $3 \mathrm{~mm}$ ). A caixa de persianas ocupa uma faixa horizontal no topo da janela com $150 \mathrm{~mm}$ de altura por $150 \mathrm{~mm}$ de profundidade (vide representação nas Figuras 1 e 2), compartimentada por duas chapas de alumínio com $1,5 \mathrm{~mm}$ de espessura, sendo a frontal (na face externa da janela), com abertura inferior de $20 \mathrm{~mm} \times 2,20 \mathrm{~m}$ para movimentação das palhetas.

As palhetas são constituídas em perfis vazados de alumínio, preenchidas com espuma expandida de poliuretano. São do tipo ventiladas, contendo perfurações tipo oblongo ao longo da horizontal, mas podendo ser ocultas/fechadas pela sobreposição das palhetas superiores, reguladas através do cordame de acionamento, posicionado na vertical direita da janela.

Figura 1 - Croquis esquemático de funcionamento de uma janela com persiana integrada, do tipo de enrolar

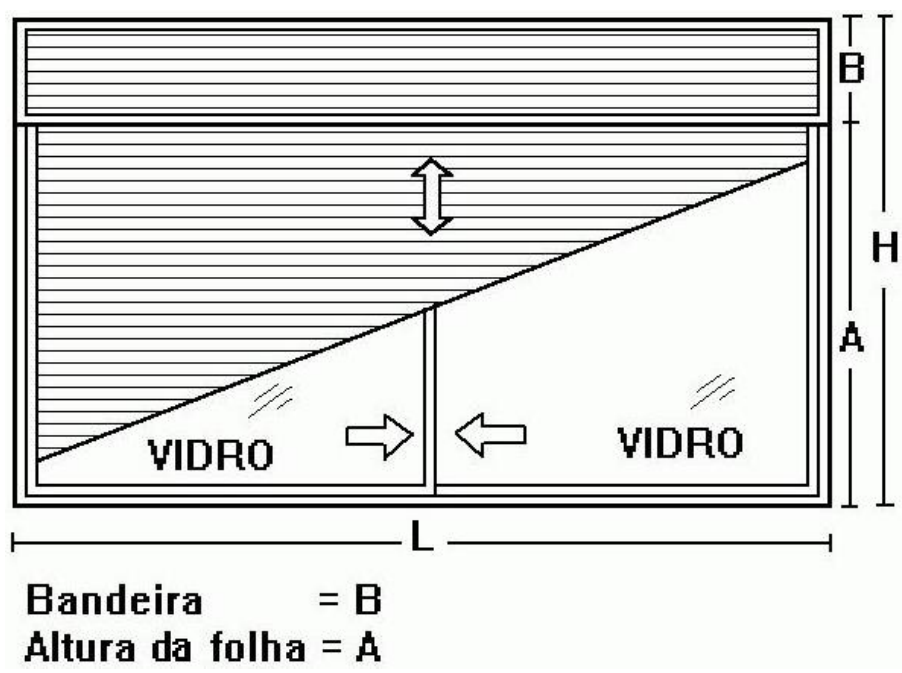

Figura 2 - Corte esquemático de funcionamento de uma caixa de persianas integrada, do tipo de enrolar

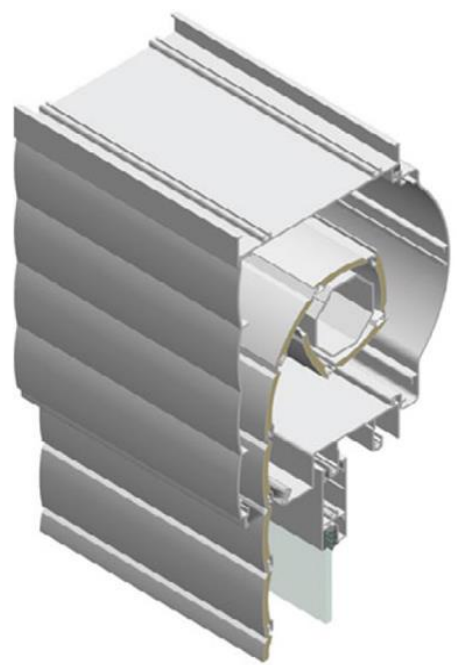

A janela foi instalada em pórtico de concreto com vão de $12 \mathrm{~m}^{2}$ (4m de largura x $3 \mathrm{~m}$ de altura), com fechamento em alvenaria de tijolos cerâmicos maciços, revestidos com argamassa em ambas as faces, com Rw de aproximadamente $48 \mathrm{~dB}$. 
A instalação da janela foi feita através do uso de contramarco em alumínio, fita espumada para separação acústica em todo o perímetro, manta absorvente no vão compreendido entre o marco do caixilho e o contramarco, bem como cordão de silicone na face externa.

\section{CONDIÇÕES DE CONTORNO E RESULTADOS DE ENSAIOS}

A janela foi ensaiada em três condições de uso, prevendo-se sempre os panos de vidro totalmente fechados, condição de maximização da isolação sonora e minimização das renovações de ar no ambiente (somente pelas eventuais frestas entre componentes), mas alterando-se as condições da persiana integrada:

a) Persiana $100 \%$ fechada ou abaixada, condição de mínima renovação de ar e de mínima iluminação interior (Figura 3);

b) Persiana "ventilando", condição de fechamento parcial onde mantém-se uma renovação de ar (com as ressalvas do parágrafo anterior) e iluminação parciais, similar à penumbra (Figura 4);

c) Persiana $100 \%$ recolhida ou levantada, condição de máxima iluminação e de ventilação/renovação de ar (com as ressalvas do parágrafo anterior) (Figura 5).

Figura 3 - Persianas $100 \%$ fechadas ou abaixadas

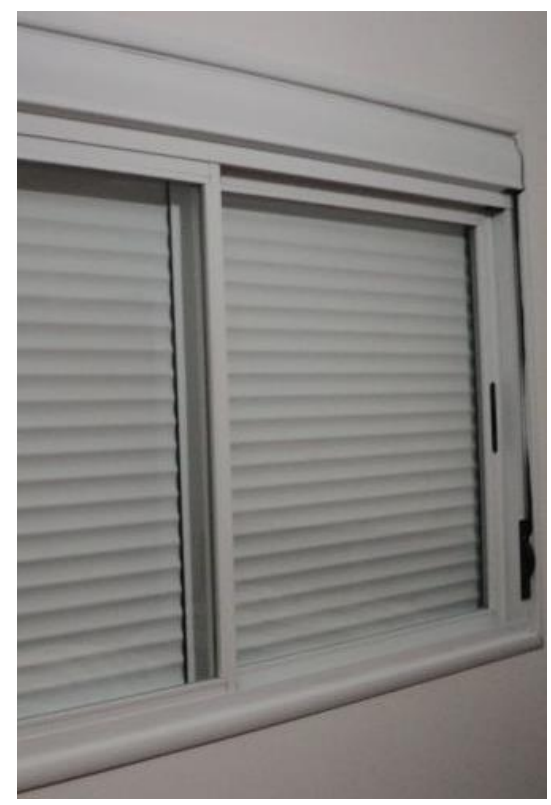

Figura 4 - Persianas "ventilando"

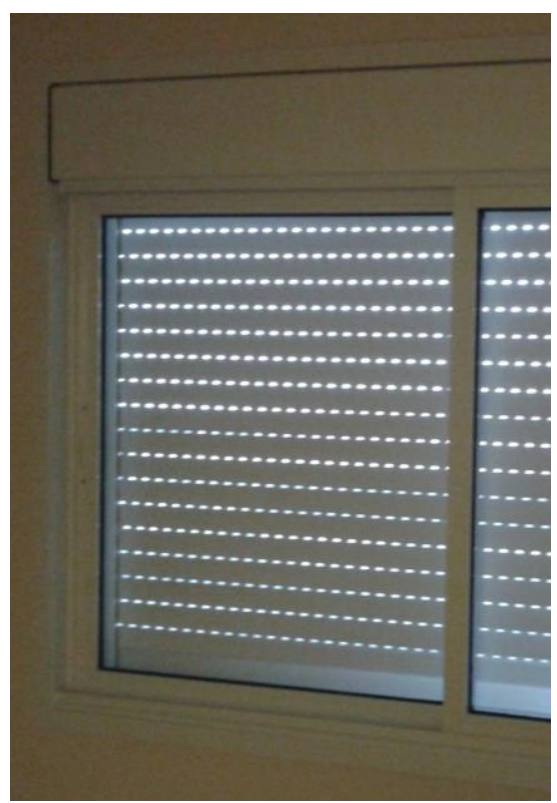

Será calculada, de maneira aproximada, a influência da contribuição das perdas referentes à isolação sonora de ruídos aéreos da janela, inserida numa situação hipotética, considerando resultados reais de cinco tipologias de sistemas construtivos para fachada e edificações habitacionais unifamiliares.

Para efeito de cálculo de contribuição da janela em relação alguns sistemas construtivos, será considerada a área de iluminação da janela, descontada a área da caixa de persiana, $\left[(2,25 \mathrm{~m} \times(1,16 \mathrm{~m}-0,15 \mathrm{~m})]=2,27 \mathrm{~m}^{2}\right.$ como correspondente a $15 \%$ da área de piso do dormitório, acompanhando a maioria dos códigos de obra das grandes cidades. Desta forma, a área de piso do dormitório é de aproximadamente $15,13 \mathrm{~m}^{2}$. 


\section{Figura 5 - Persianas $100 \%$ recolhidas ou levantadas}

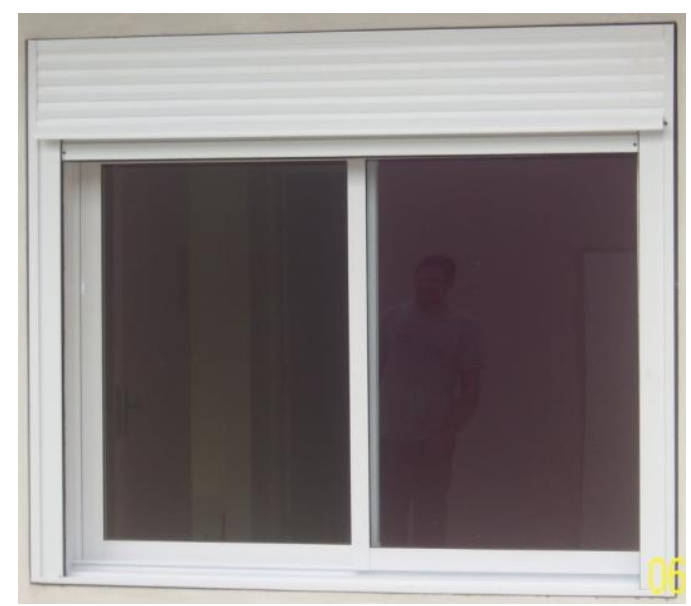

Supondo-se comumente ambiente com planta em formato levemente retangular, vamos considerar que teremos aproximadamente $4,4 \mathrm{~m}$ de fachada por $3,4 \mathrm{~m}$ de profundidade. $\mathrm{O}$ pé-direito mais usual em edificações habitacionais unifamiliares é de $2,7 \mathrm{~m}$, portanto, a área da fachada na qual a janela estaria contida seria de aproximadamente $4,4 \mathrm{~m} \times 2,7 \mathrm{~m}$ $=12 \mathrm{~m}^{2}$.

Visando a simplificação do processo de cálculo e, devido ao caráter de aproximação da avaliação, será considerada a fachada como única mão de direção para o ruído, tendendo a zero os demais caminhos/vias de propagação do som. Outrossim, a geometria entre a parede considerada em campo, suas vinculações e demais contornos serão considerados simplificados e equivalentes aos elementos constituídos nos pórticos de ensaio.

Serão considerados os seguintes sistemas construtivos (Figura 6):

a) Parede maciça de concreto armado, espessura total de $150 \mathrm{~mm}$, sem revestimento, fck estimado de $25 \mathrm{MPa} ; \mathrm{Rw}=45 \mathrm{~dB}$;

b) Parede mista, em concreto armado, contendo blocos cerâmicos vazados, tipo lajota cerâmica em seu interior, espessura total de aproximadamente $115 \mathrm{~mm}$, espessura de concreto de $55 \mathrm{~mm}$, fck estimado de $25 \mathrm{Mpa}$; $\mathrm{Rw}=41 \mathrm{~dB}$;

c) Parede de blocos de concreto, tipo vedação, $140 \mathrm{~mm}$ de espessura, com $5 \mathrm{~mm}$ de revestimento em cada face (argamassa externamente e gesso internamente); Rw $=39 \mathrm{~dB}$;

d) Parede de blocos cerâmicos estruturais, espessura de $140 \mathrm{~mm}$, com $5 \mathrm{~mm}$ de revestimento em cada face (argamassa externamente e gesso internamente); $\mathrm{Rw}$ $=38 \mathrm{~dB}$;

e) Parede de blocos cerâmicos de vedação, furo na horizontal, espessura de $115 \mathrm{~mm}$, com $5 \mathrm{~mm}$ de revestimento em cada face (argamassa externamente e gesso internamente); $\mathrm{Rw}=37 \mathrm{~dB}$.

O gráfico dos resultados dos ensaios das paredes elencadas, contendo o Índice de Redução Sonora $(\mathrm{R})$ para dadas frequências representativas em terços de oitava encontra-se na Figura 3.

Os resultados dos ensaios com a janela, contendo o Índice de Redução Sonora $(\mathrm{R})$ para dadas frequências representativas em terços de oitava, variando-se as condições de abertura/fechamento da persiana integrada encontram-se na Figura 7. 
Depreende-se pela observação do gráfico que o efeito de posicionamento da persiana dá-se a partir das médias frequências, apresentando maior influência no desempenho quanto às altas frequências.

Figura 6 - Gráfico comparativo entre os cinco sistemas construtivos a considerar nos cálculos de influência empregando-se a janela alvo do estudo

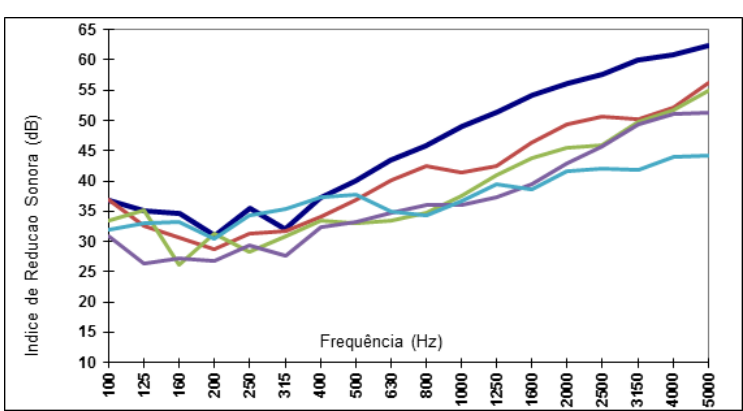

\begin{tabular}{|l|l|}
\hline \multicolumn{1}{|c|}{ Legenda } & $\begin{array}{l}\text { Concreto armado, } \\
150 \mathrm{~mm}, \text { sem } \\
\text { revestimento, Rw } \\
45 \mathrm{~dB}\end{array}$ \\
\hline $\begin{array}{l}\text { Concreto armado } \\
\text { misto, com lajotas } \\
\text { cerâmicas, } 115 \mathrm{~mm}, \\
\text { revestido, Rw }= \\
41 \mathrm{~dB}\end{array}$ & $\begin{array}{l}\text { Bloco concreto } \\
\text { vedação, } 140 \mathrm{~mm}, \\
\text { revestido, Rw }=39 \mathrm{~dB}\end{array}$ \\
\hline $\begin{array}{l}\text { Bloco cerâmico } \\
\text { estrutural, } 140 \mathrm{~mm}, \\
\text { revestido, Rw }= \\
38 \mathrm{~dB}\end{array}$ & $\begin{array}{l}\text { Bloco cerâmico } \\
\text { vedação, furo } \\
\text { horizontal, } 115 \mathrm{~mm}, \\
\text { revestido, Rw }=37 \mathrm{~dB}\end{array}$ \\
\hline
\end{tabular}

Figura 7 - Gráfico comparativo entre as três condições de abertura/fechamento da persiana empregando-se a janela alvo do estudo

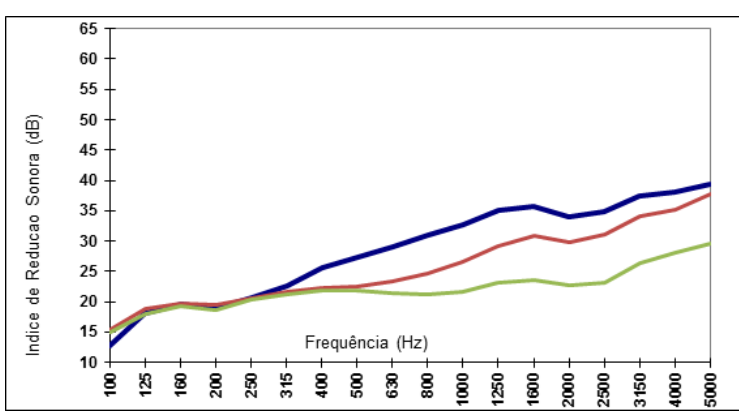

\begin{tabular}{|c|c|}
\hline Legenda & $\begin{array}{l}\text { Persianas } 100 \% \\
\text { abaixadas, } \mathrm{Rw}= \\
31 \mathrm{~dB}\end{array}$ \\
\hline $\begin{array}{l}\text { Persianas } \\
\text { "ventilando"; Rw = } \\
27 \mathrm{~dB}\end{array}$ & $\begin{array}{l}\text { Persianas } 100 \% \\
\text { recolhidas, } \mathrm{Rw}= \\
23 \mathrm{~dB} \text {. }\end{array}$ \\
\hline
\end{tabular}

\section{CÁLCULOS E CONSIDERAÇÕES}

A isolação sonora em sistemas compostos por parede e janela ou, a perda na transmissão de partições compostas (BISTAFA, 2011), dá-se pela perda na transmissão de seus componentes individuais, por meio da expressão:

$$
\tau_{c}=\frac{\sum_{i=1}^{N} S_{i} \tau_{i}}{\sum_{i=1}^{N} S_{i}}
$$

Onde:

$\tau_{c}=$ coeficiente de transmissão sonora da partição composta;

$S_{i}=$ área do $i$ - ésimo componente da partição

$\tau_{i}=$ respectivo coeficiente de transmissão sonora

Em que:

$$
\tau_{i}=10^{-P T_{i} / 10}
$$

Onde:

$P T_{i}=$ perda na transmissão do $i$ - ésimo componente $\tau_{c} 2,25 \mathrm{~m} \times 1,16 \mathrm{~m}=2,61 \mathrm{~m}^{2}$

$\tau_{c} 2,25 \mathrm{mx} 1,16 \mathrm{~m}=2,61 \mathrm{~m}^{2}$ 
Calculou-se o efeito da inserção da janela nas tipologias de parede consideradas (Figuras 8, 9, 10, 11 e 12)

Figura 8 - Parede de concreto armado, $150 \mathrm{~mm}$, sem revestimento. Influência das três condições de abertura/fechamento da persiana empregando-se a janela alvo do estudo

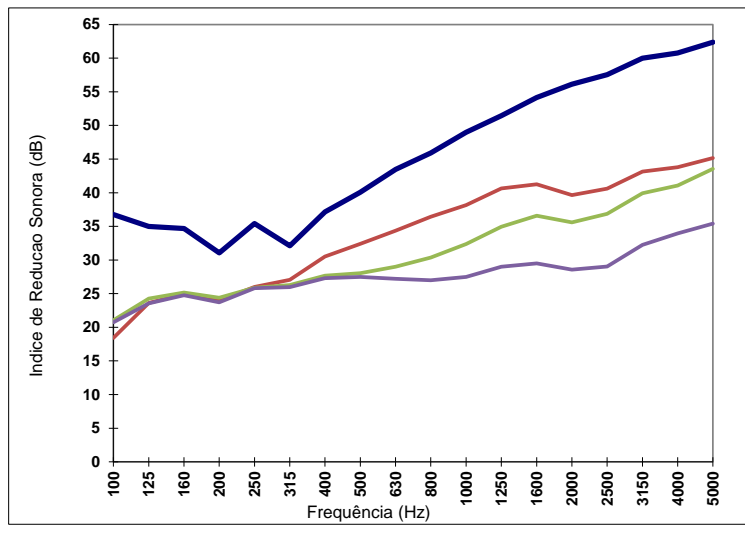

\begin{tabular}{|l|l|}
\hline \multicolumn{2}{|c|}{ Legenda } \\
\hline $\begin{array}{l}\text { Concreto armado, } \\
150 \mathrm{~mm}, \text { sem } \\
\text { revestimento, } \mathrm{Rw}= \\
45 \mathrm{~dB}\end{array}$ & $\begin{array}{l}\text { Parede + janela } \\
\text { com persianas } \\
100 \% \text { fechadas, } \\
\mathrm{Rw}=36 \mathrm{~dB} .\end{array}$ \\
\hline $\begin{array}{l}\text { Parede + janela com } \\
\text { persianas } \\
\text { "ventilando"; Rw }= \\
\text { 33dB }\end{array}$ & $\begin{array}{l}\text { Parede + janela } \\
\text { com persianas } \\
100 \% \text { abertas, } \mathrm{Rw} \\
=29 \mathrm{~dB}\end{array}$ \\
\hline
\end{tabular}

Figura 10 - Parede de blocos de concreto tipo vedação, revestida, $140 \mathrm{~mm}$ - Influência das três condições de abertura/fechamento da persiana empregando-se a janela alvo do estudo

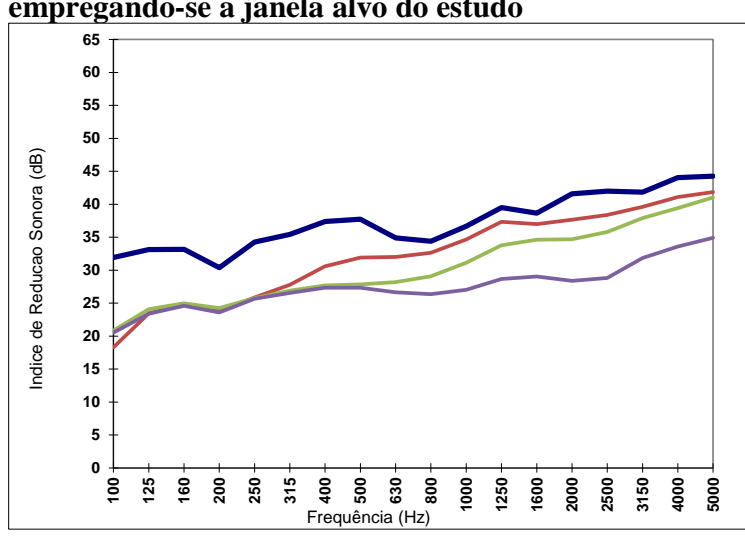

\begin{tabular}{|l|l|l|}
\hline \multicolumn{2}{|c|}{ Legenda } \\
\hline $\begin{array}{l}\text { Bloco concreto } \\
\text { vedação, 140mm, } \\
\text { revestido, Rw = 39dB }\end{array}$ & $\begin{array}{l}\text { Parede + janela } \\
\text { com persianas } \\
100 \% \text { fechadas, } \\
\mathrm{Rw}=35 \mathrm{~dB} .\end{array}$ \\
\hline $\begin{array}{l}\text { Parede + janela com } \\
\text { persianas } \\
\text { "ventilando"; Rw }= \\
\text { 32dB }\end{array}$ & $\begin{array}{l}\text { Parede + janela } \\
\text { com persianas } \\
100 \% \text { abertas, } \mathrm{Rw} \\
=28 \mathrm{~dB}\end{array}$ \\
\hline
\end{tabular}

Figura 9 - Parede de concreto armado misto, com lajotas cerâmicas, $115 \mathrm{~mm}$, revestida - Influência das três condições de abertura/fechamento da persiana empregando-se a janela alvo do estudo

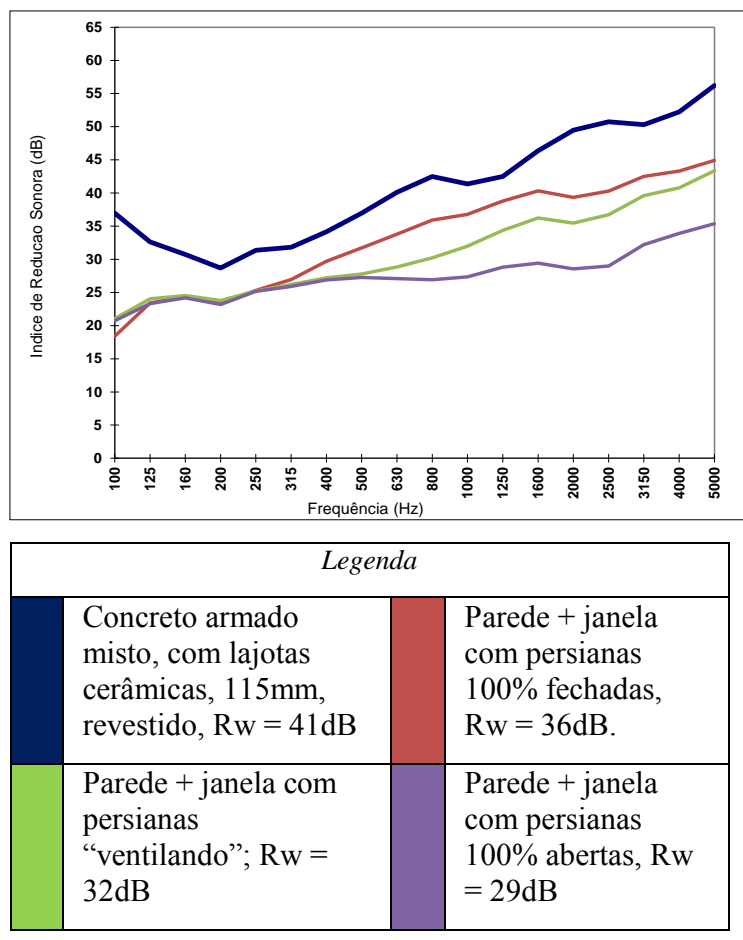

Figura 11 - Parede de bloco cerâmico estrutural, $140 \mathrm{~mm}$, revestido - Influência das três condições de abertura/fechamento da persiana empregando-se a janela alvo do estudo

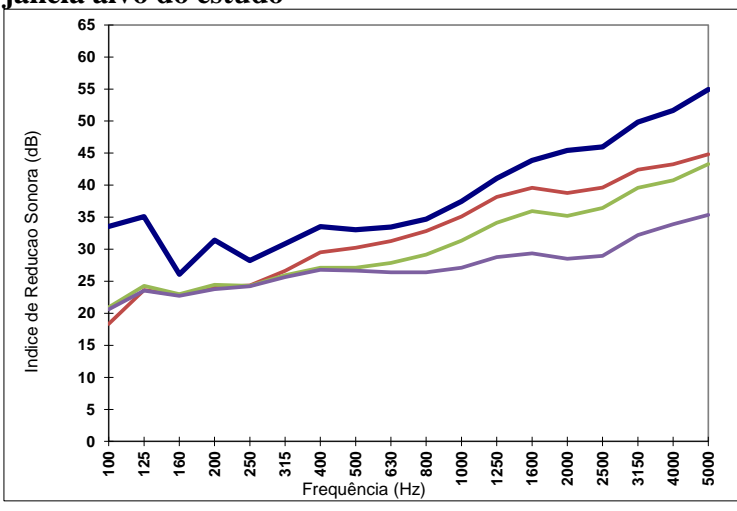

\begin{tabular}{|l|l|l|}
\hline \multicolumn{3}{|c|}{ Legenda } \\
\hline $\begin{array}{l}\text { Bloco cerâmico } \\
\text { estrutural, 140mm, } \\
\text { revestido, Rw = 38dB }\end{array}$ & $\begin{array}{l}\text { Parede + janela } \\
\text { com persianas } \\
100 \% \text { fechadas, } \\
\mathrm{Rw}=35 \mathrm{~dB} .\end{array}$ \\
\hline $\begin{array}{l}\text { Parede + janela com } \\
\text { persianas } \\
\text { "ventilando"; Rw }= \\
\text { 32dB }\end{array}$ & $\begin{array}{l}\text { Parede + janela } \\
\text { com persianas } \\
100 \% \text { abertas, Rw } \\
=28 \mathrm{~dB}\end{array}$ \\
\hline
\end{tabular}


Figura 12 - Parede de bloco cerâmico de vedação, furo horizontal, $115 \mathrm{~mm}$, revestida - Influência das três condições de abertura/fechamento da persiana empregando-se a janela alvo do estudo

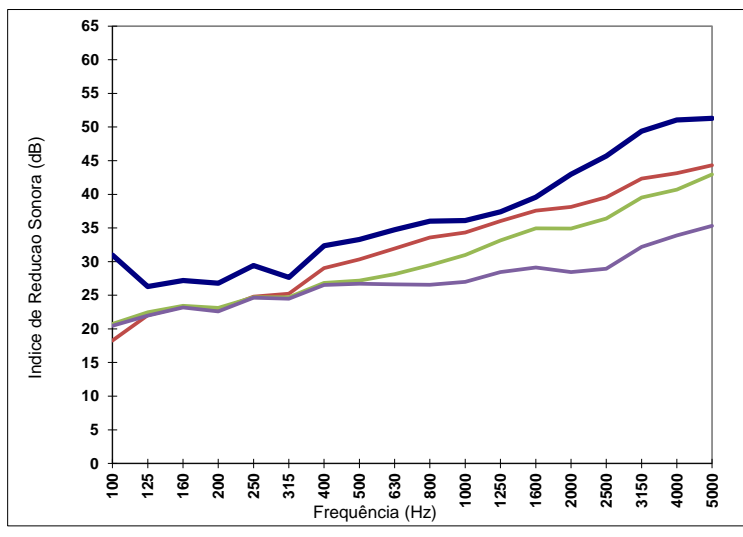

\begin{tabular}{|l|l|l|}
\hline \multicolumn{3}{|c|}{ Legenda } \\
\hline \hline & $\begin{array}{l}\text { Bloco cerâmico } \\
\text { vedação, furo } \\
\text { horizontal, 115mm, } \\
\text { revestido, Rw = 37dB }\end{array}$ & $\begin{array}{l}\text { Parede + janela } \\
\text { com persianas } \\
100 \% \text { fechadas, } \\
\mathrm{Rw}=34 \mathrm{~dB} .\end{array}$ \\
\hline $\begin{array}{l}\text { Parede + janela com } \\
\text { persianas } \\
\text { "ventilando"; Rw }=\end{array}$ & $\begin{array}{l}\text { Parede + janela } \\
\text { com persianas } \\
100 \% \text { abertas, } \mathrm{Rw} \\
\text { 32dB }\end{array}$ & $28 \mathrm{~dB}$ \\
\hline
\end{tabular}

O efeito da inserção da janela nas tipologias de parede consideradas encontra-se resumido no Quadro 1, considerando-se a classificação segundo a NBR 15575-4, Tabela F.11 - Índice de redução sonora ponderado, $\mathrm{Rw}$ de fachadas para ensaios em laboratório.

Quadro 1 - Influência das três condições de abertura/fechamento da persiana empregando-se a janela alvo do estudo considerando os critérios de desempenho da NBR 15575-4 para ensaios em laboratório

\begin{tabular}{|c|c|c|c|c|c|c|}
\hline \multirow[b]{2}{*}{ Tipologia de parede } & \multicolumn{2}{|r|}{ Critérios } & \multicolumn{4}{|c|}{ Rw considerando: } \\
\hline & $\begin{array}{l}\mathrm{Rw} \\
(\mathrm{dB})\end{array}$ & $\begin{array}{c}\text { Classe de ruído e Nível de } \\
\text { desempenho }\end{array}$ & 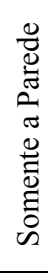 & 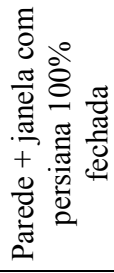 & 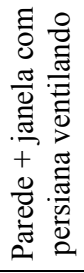 & 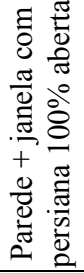 \\
\hline \multirow{10}{*}{$\begin{array}{l}\text { Parede maciça de concreto } \\
\text { armado, espessura total de } \\
150 \mathrm{~mm} \text {, sem revestimento, } \\
\text { fck estimado de } 25 \mathrm{MPa}\end{array}$} & \multicolumn{2}{|r|}{ Resultados $=>$} & 45 & 36 & 33 & 29 \\
\hline & $>=25$ & Classe I, Nível M & & & & \\
\hline & \multirow{2}{*}{$>=30$} & Classe I, Nível I & & & & \\
\hline & & Classe II, Nível M & & & & \\
\hline & \multirow{3}{*}{$>=35$} & Classe I, Nível S & & & & \\
\hline & & Classe II, Nível I & & & & \\
\hline & & Classe III, Nível M & & & & \\
\hline & \multirow{2}{*}{$>=40$} & Classe II, Nível S & & & & \\
\hline & & Classe III, Nível I & & & & \\
\hline & $>=45$ & Classe III, Nível S & & & & \\
\hline \multirow{10}{*}{$\begin{array}{l}\text { Parede mista, em concreto } \\
\text { armado, contendo blocos } \\
\text { cerâmicos vazados, tipo } \\
\text { lajota cerâmica em seu } \\
\text { interior, espessura total de } \\
\text { aproximadamente } 115 \mathrm{~mm} \text {, } \\
\text { espessura de concreto de } \\
55 \mathrm{~mm}, \text { fck estimado de } \\
25 \mathrm{Mpa}\end{array}$} & \multicolumn{2}{|r|}{ Resultados $=>$} & 41 & 36 & 32 & 29 \\
\hline & $>=25$ & Classe I, Nível M & & & & \\
\hline & \multirow{2}{*}{$>=30$} & Classe I, Nível I & & & & \\
\hline & & Classe II, Nível M & & & & \\
\hline & \multirow{3}{*}{$>=35$} & Classe I, Nível S & & & & \\
\hline & & Classe II, Nível I & & & & \\
\hline & & Classe III, Nível M & & & & \\
\hline & \multirow{2}{*}{$>=40$} & Classe II, Nível S & & & & \\
\hline & & Classe III, Nível I & & & & \\
\hline & $>=45$ & Classe III, Nível S & & & & \\
\hline
\end{tabular}




\begin{tabular}{|c|c|c|c|c|c|c|}
\hline \multirow{10}{*}{$\begin{array}{c}\text { Parede de blocos de } \\
\text { concreto, tipo vedação, } \\
\text { 140mm de espessura, com } \\
5 \mathrm{~mm} \text { de revestimento em } \\
\text { cada face (argamassa } \\
\text { externamente e gesso } \\
\text { internamente) }\end{array}$} & \multicolumn{2}{|r|}{ Resultados $=>$} & 39 & 35 & 32 & 28 \\
\hline & $>=25$ & Classe I, Nível M & & & & \\
\hline & \multirow{2}{*}{$>=30$} & Classe I, Nível I & & & & \\
\hline & & Classe II, Nível M & & & & \\
\hline & \multirow{3}{*}{$>=35$} & Classe I, Nível S & & & & \\
\hline & & Classe II, Nível I & & & & \\
\hline & & Classe III, Nível M & & & & \\
\hline & \multirow{2}{*}{$>=40$} & Classe II, Nível S & & & & \\
\hline & & Classe III, Nível I & & & & \\
\hline & $>=45$ & Classe III, Nível S & & & & \\
\hline \multirow{10}{*}{$\begin{array}{l}\text { Parede de blocos cerâmicos } \\
\text { estruturais, espessura de } \\
140 \mathrm{~mm} \text {, com } 5 \mathrm{~mm} \text { de } \\
\text { revestimento em cada face } \\
\text { (argamassa externamente e } \\
\text { gesso internamente) }\end{array}$} & \multicolumn{2}{|r|}{ Resultados $=>$} & 38 & 35 & 32 & 28 \\
\hline & $>=25$ & Classe I, Nível M & & & & \\
\hline & \multirow{2}{*}{$>=30$} & Classe I, Nível I & & & & \\
\hline & & Classe II, Nível M & & & & \\
\hline & \multirow{3}{*}{$>=35$} & Classe I, Nível S & & & & \\
\hline & & Classe II, Nível I & & & & \\
\hline & & Classe III, Nível M & & & & \\
\hline & \multirow{2}{*}{$>=40$} & Classe II, Nível S & & & & \\
\hline & & Classe III, Nível I & & & & \\
\hline & $>=45$ & Classe III, Nível S & & & & \\
\hline \multirow{10}{*}{$\begin{array}{l}\text { Parede de blocos cerâmicos } \\
\text { de vedação, furo na } \\
\text { horizontal, espessura de } \\
115 \mathrm{~mm} \text {, com } 5 \mathrm{~mm} \text { de } \\
\text { revestimento em cada face } \\
\text { (argamassa externamente e } \\
\text { gesso internamente) }\end{array}$} & & Resultados $=>$ & 37 & 34 & 32 & 28 \\
\hline & $>=25$ & Classe I, Nível M & & & & \\
\hline & \multirow{2}{*}{$>=30$} & Classe I, Nível I & & & & \\
\hline & & Classe II, Nível M & & & & \\
\hline & \multirow{3}{*}{$>=35$} & Classe I, Nível S & & & & \\
\hline & & Classe II, Nível I & & & & \\
\hline & & Classe III, Nível M & & & & \\
\hline & \multirow{2}{*}{$>=40$} & Classe II, Nível S & & & & \\
\hline & & Classe III, Nível I & & & & \\
\hline & $>=45$ & Classe III, Nível S & & & & \\
\hline
\end{tabular}

\begin{tabular}{|l|l|l|l|}
\hline \multicolumn{3}{|c|}{ Legenda } \\
\hline Atende aos critérios & & Não atende aos critérios \\
\hline
\end{tabular}

\section{CONCLUSÕES}

A janela em estudo apresenta um razoável índice de redução sonora (31dB com todas as folhas fechadas), sendo um produto empregado em projetos habitacionais de médio e alto padrões devido à relativa robustez da construção da linha com perfis de alumínio anodizado, emprego de pintura eletrostática a pó, vidros laminados de $6 \mathrm{~mm}$, gaxetas e escovas de cerdas como elementos de vedação bem como emprego de mantas isolantes junto ao contramarco. Todos esses elementos elevam o custo de aquisição do produto, tornando-se segmentado nesta categoria de mercado.

Quanto ao efeito de movimentação da persiana, depreende-se da análise dos dados que caso o usuário queira o ambiente iluminado, seja na penumbra ou em sua totalidade, tal se dará ao elevado custo de abdicar de boa parte dos ganhos de desempenho acústico do 
sistema. A janela, isoladamente, obteve resultados variando em $4 \mathrm{~dB}$ para cada condição de abertura: $31 \mathrm{~dB}$, persiana 100\% fechada, ambiente interno na escuridão; $27 \mathrm{~dB}$, persiana ventilando, ambiente interno na penumbra e $23 \mathrm{~dB}$, persiana $100 \%$ recolhida, ambiente interno com máxima iluminação natural.

Contudo, mesmo a inserção de produto de desempenho razoável em paredes de várias tipologias com variados índices de desempenho acústico, faz com que o sistema tenha um decaimento de desempenho significativo. Esse efeito se dará em magnitude proporcional à relação entre as áreas da janela e da alvenaria e com os respectivos índices de desempenho de cada uma das partições. Observa-se pelos gráficos e pelos quadros apresentados que:

a)Quanto maior o desempenho isolado da parede, maior será o impacto da inserção de uma janela ou porta-balcão com desempenho intermediário ou inferior;

b)Paredes com desempenho intermediários e limítrofes sofrem menor impacto dessa inserção, pois as mesmas possuem, aproximadamente, desempenhos similares;

Quando combinados os desempenhos das paredes com a janela inserida nas mesmas, considerando-se a movimentação da persiana, observa-se o declínio acentuado de desempenho do sistema, desqualificando o sistema em vários níveis e classes de desempenho.

Janelas desta tipologia são geralmente ensaiadas com a folha de vidro e as persianas totalmente fechadas. Verificou-se que a diferença quanto à isolação sonora é relevante e ela deve ser levada em conta pelo projetista que não deve considerar somente $o$ potencial máximo de isolação sonora como também outras configurações na qual a janela venha a ser utilizada.

Recomenda-se para janelas de tipologia mista (com mais de um tipo de folha) que sejam considerados, em termos normativos, as várias combinações de movimentações de folhas, partindo-se do pressuposto mínimo da iluminação natural em sua plenitude, ou seja, considerar também os ensaios com as folhas tipo persiana (ou palhetas, nos casos de movimentação de abrir e outras) abertas e/ou recolhidas na posição de máxima iluminação.

\section{REFERÊNCIAS}

ASSOCIAÇÃO BRASILEIRA DE NORMAS TÉCNICAS (ABNT). NBR-15575-4:

Edificações habitacionais - Desempenho. Parte 4: Requisitos para os sistemas de vedações verticais internas e externas - SVVIE . Rio de Janeiro, 2013.

BISTAFA, Sylvio R. "Acústica aplicada ao controle do ruído”, 2a edição, São Paulo, 2011.

INTERNATIONAL ORGANIZATION FOR STANDARDIZATION (ISO). ISO-10140-2:

Acoustics - Laboratory measurement of sound insulation of building elements - Part 2:

Mesurement of airborne sound insulation. Switzerland, 2010.

ISO 717-1: Acoustics -Rating of sound insulation in buildings and of building elements - Part 1: Airborne sound insulation. Switzerland, 2013.

SÃO PAULO, Prefeitura do Município de - "Código de Obras e Edificações - COE Lei no 11.228/92" - in http://www.prefeitura.sp.gov.br/cidade/secretarias/ subprefeituras/upload/pinheiros/arquivos/COE_1253646799.pdf 